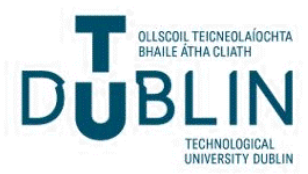

Technological University Dublin

ARROW@TU Dublin

Articles

School of Electrical and Electronic Engineering

2013-10

\section{Footwear Antennas for Body Area Telemetry}

Domenico Gaetano

Technological University Dublin, domenico.gaetano@mydit.ie

Patrick McEvoy

Technological University Dublin, patrick.mcevoy@tudublin.ie

Max Ammann

Technological University Dublin, max.ammann@tudublin.ie

See next page for additional authors

Follow this and additional works at: https://arrow.tudublin.ie/engscheleart2

Part of the Biomedical Commons, Electrical and Electronics Commons, and the Electromagnetics and Photonics Commons

\section{Recommended Citation}

D. Gaetano, P. McEvoy, M. J. Ammann, J. E. Browne, L. Keating and F. Horgan, (2013) "Footwear Antennas for Body Area Telemetry," Antennas \& Propagation, IEEE Transactions on, vol. 61, no.10, pp.4908-4916 doi:10.1109/TAP.2013.2272451

This Article is brought to you for free and open access by the School of Electrical and Electronic Engineering at ARROW@TU Dublin. It has been accepted for inclusion in Articles by an authorized administrator of ARROW@TU

Dublin. For more information, please contact

arrow.admin@tudublin.ie, aisling.coyne@tudublin.ie, gerard.connolly@tudublin.ie.

Funder: Science Foundation Ireland

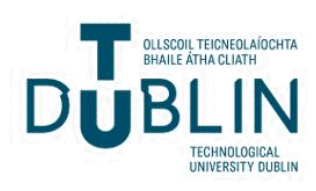


Authors

Domenico Gaetano, Patrick McEvoy, Max Ammann, Jacinta Browne, Louise Keating, and Frances Horgan

This article is available at ARROW@TU Dublin: https://arrow.tudublin.ie/engscheleart2/68 


\title{
Footwear Antennas for Body Area Telemetry
}

\author{
D. Gaetano, Student Member IEEE, P. McEvoy, Member IEEE, M. J. Ammann, Senior Member IEEE, \\ J. E. Browne, L. Keating and F. Horgan
}

Full Citation: D. Gaetano, P. McEvoy, M. J. Ammann, J. E. Browne, L. Keating and F. Horgan, "Footwear Antennas for Body Area Telemetry," Antennas \& Propagation, IEEE Transactions on, vol. 61, no.10, pp.4908-4916

DOI: 10.1109/TAP.2013.2272451

URL: http://ieeexplore.ieee.org/xpl/articleDetails.jsp?tp=\&arnumber=6555931

\begin{abstract}
Antennas designed to link footwear sensors within body centric networks are introduced with two small UWB antennas, one directional and another quasi-omnidirectional. The radiating characteristics are evaluated for three positions on a sample sports shoe using a detailed simulation model and measurements with a homogenous foot phantom. Antenna performance is assessed for resilience to close proximity loading by the footwear materials and the phantom foot.
\end{abstract}

\section{INTRODUCTION}

Antenna design for body centric communications is predominantly reported for upper body applications [1-6]. While some research describes antennas for placement near ankles [7], antennas for footwear telemetry links are not detailed. It is envisaged that medical and sporting applications will be developed to monitor real-time sensor data from footwear in order to analyze a subject's gait and baropodometrics [8], [9]. Miniaturized [10] short-range radios can connect with on-body or off-body systems and it is deemed essential to avoid bulky [11] footwear fixtures that might affect spatio-temporal gait characteristics.

Electrically small antennas radiate as a function of their close proximity surroundings [12]. Design and performance considerations for footwear antennas should include, inter alia, the constituent material properties and shapes of footwear, the movement of the subject and the characteristic propagation environment. Selection of the positions suited to antennas relate to how the sensors are integrated, the resilience to material flexing and the line-of-sight visibility to the upper body or to off-body data stations. The close and varying proximity of the antenna to the ground surface beneath a foot is subject to propagation fast-fading [13]. Ultra wideband (UWB) offers a suitable propagation range for body area networks [14] and the spectrum bandwidth can offset the impact of multipath fading. Low powered UWB radio modules are commercially available.

The limited literature on antennas for footwear devices include a patent for a narrowband inverted-F antenna for a pedometer linked to a portable phone [15], a 2-element planar array for a radar-assisted walking aid [16], a shoe mounted GPS [17] antenna and an RFID antenna linked to motion energy harvesting [18]. The emerging technologies indicate that improved analysis and design of antennas will enable smart footwear applications.

Two UWB antenna designs are implemented for the small areas available on the shoe surface. A monopole type is designed for the toe-box of the shoe for the ventral side of the coronal plane. A directional Vivaldi type that is suited to the lateral quarter of the shoe to serve that side of the sagittal plane and to the heel counter to connect with dorsal side of the coronal plane.

Due to the high computational loading of the foot/shoe model, the initial designs were modeled in free-space before being assessed and optimized on the footwear. The simulated and measured results demonstrate how the designs interact with the footwear.

Section II provides details on the experimental method, the materials used and the modeling approach. Section III reports the monopole antenna design and its performance on the toe-box area of the shoe. Section IV shows the Vivaldi design and its fit to the lateral quarter and heel counter areas on the shoe. Finally, section V summaries a series of E-field distribution for the antennas on full body models and outlines the connectivity of the footwear with the upper-body and off-body areas.

\section{Methodology}

Computer simulations and anechoic chamber measurements were used to evaluate how various antennas would perform on footwear. Candidate antenna types were considered for suitable radiation patterns from different locations around the footwear. Numerical models were run using CST Microwave Studio ${ }^{\circledR}$ on a $2.40 \mathrm{GHz}$ quad-core processor PC with 12 Gbytes of memory. Two NVIDIA ${ }^{\circledR}$ Tesla C1026 accelerator cards were used to reduce the experimental time to circa nine hours for the extended processing for finer resolution models.

\section{A. Shoe Model}

In order to compare equivalent results from simulated and measured experiments, the geometric and dielectric properties of the numerical model were derived from measurements of a sample shoe. Orthographic perspective photographs were 
processed using photogrammetry with the Blender [19] software application to construct a 3D model for import into CST Microwave Studio, shown in Fig. 1. The shoe upper comprises fabric and leather parts, for which the permittivity was measured using a coaxial probe [20] at conceivable mounting positions at the toe-box, lateral quarter and heel counter. Similar dielectric values were recorded and the average was used to define the shoe upper electrical properties. The rubber sole was also measured and the values used in the model are shown in Fig. 2.
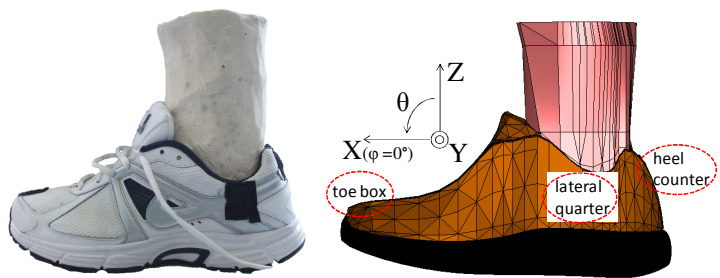

Fig. 1. Photograph and CST model with reference system of the dielectric loaded shoe.
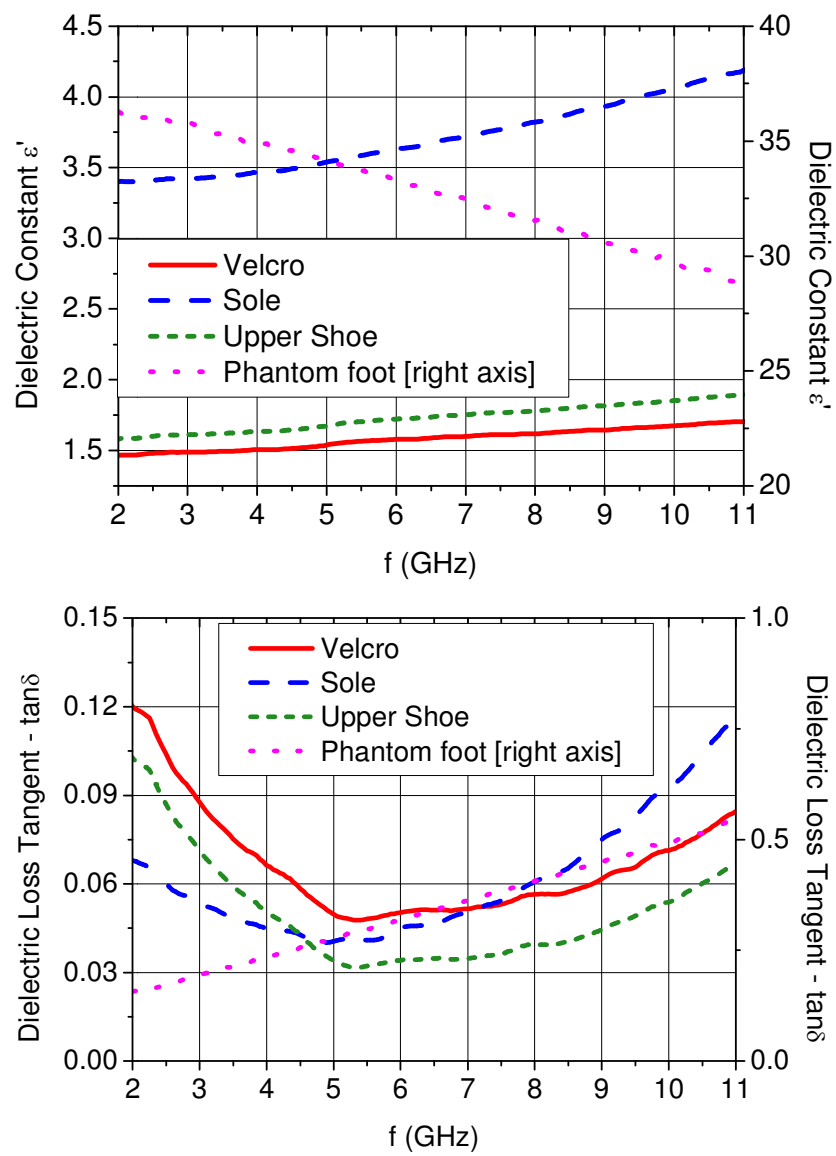

Fig. 2. Measured dielectric properties of the shoe and phantom foot.

\section{B. Foot Phantom and Model}

A foot-shaped homogeneous tissue-equivalent phantom was manufactured as a reference in-shoe dielectric load for antenna measurements. The materials listed in Table 1 [21] were mixed with the prescribed volumes and were formed in a foot-shaped mold.

TABLE I

PHANTOM INGREDIENTS

\begin{tabular}{|c|c|}
\hline Material & Quantity [g] \\
\hline Deionized water & 481.3 \\
\hline Agar & 14.9 \\
\hline Polyethylene Powder & 144.4 \\
\hline Sodium Chloride & 1.0 \\
\hline TX - 151 & 4.3 \\
\hline Dehydroacetic Acid Sodium Salt & 0.3 \\
\hline Total & 646.2 \\
\hline
\end{tabular}

The formula provides for a permittivity of a two-thirds muscle for an equivalent bulk representation of the skin, fat and muscle tissues. Dielectric probe measurements of the material in the phantom were then used to define the properties of the 
simulated foot model. Two interconnecting Velcro layers with a mated thickness of $3 \mathrm{~mm}$ were used to fix the prototype antennas to the various positions on the shoe. The Velcro enabled slight flexing of the antennas to better fit the partially curved shoe surfaces and allowed for stable repeatible measurements [22].

\section{Human Body model}

The human body models were developed using the "Make Human" application [23]. This supports the modification of the general physical features of weight, height and age; and for local length and radii dimenions of the limbs, neck, etc. Models in the various stances are available and were the basis of an electromagnetic model for whole body E-field simulations. The walking process is characterised by 299 frames through the normal motion of the body. An .obj file is exported to CST Microwave Studio ${ }^{\circledR}$ and following some geometric corrections, it can be modeled as a homogeneous dielectric structure.

\section{MONOPOlE ANTENNA DESIGN}

\section{A. Monopole Antenna}

A monopole antenna, shown in Fig. 3 is designed on a single-sided FR-4 dielectric with 0.2 mm thickness. A coplanar waveguide feed is used to match the SMA connector to the antenna input impedance while maintaining small dimensions.

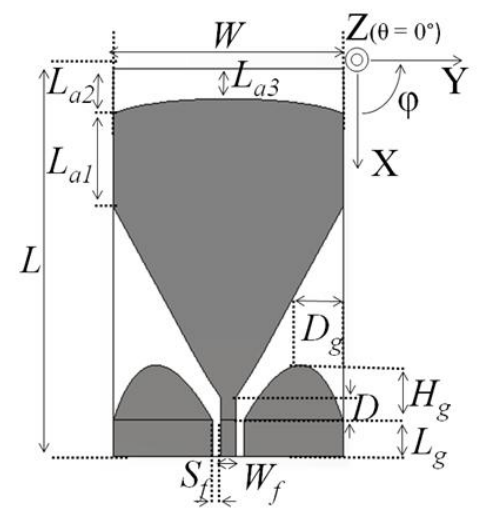

Fig. 3. Monopole Antenna.

The geometric parameters were optimized [24] for the footwear with a multi-objective algorithm for a quasiomnidirectional pattern with impedance matching in the $6-8.5 \mathrm{GHz}$ band [25]. The maximum dimensions of the device were limited to minimize the overlay area on the shoe. The final dimensions were $W=15.7 \mathrm{~mm}, L=25.63 \mathrm{~mm}, W_{f}=1 \mathrm{~mm}$, $S_{f}=0.56 \mathrm{~mm}, L_{g}=2.4 \mathrm{~mm}, H_{g}=3.6 \mathrm{~mm}, L_{a l}=6.17 \mathrm{~mm}, L_{a 2}=2.96 \mathrm{~mm}, L_{a 3}=2 \mathrm{~mm}, D=1.47 \mathrm{~mm}, D_{g}=3.2 \mathrm{~mm} . \mathrm{The}$ CPW groundplane was refined to decouple surface currents that interacted with the end-fire behavior of the slot line at higher frequencies in order to keep the radiation pattern omnidirectional. The $\mathrm{S}_{11}$ achieves $-10 \mathrm{~dB}$ match across $6-8.5 \mathrm{GHz}$ for simulation and measurement. Discrepancies at out-of-band low frequencies are attributed to interaction of surface currents on the measurement cable from the small ground plane [26]. Comparing simulated and measured free-space radiation patterns indicates that the design produced a quasi-omnidirectional pattern in the $\varphi=90^{\circ}$ plane. Considering the $6-8.5 \mathrm{GHz}$ bandwidth, the mean value of the simulated realized gain in the $\varphi=90^{\circ}$ plane $\left(-180^{\circ}<\theta<180^{\circ}\right)$ is greater than $1 \mathrm{dBi}$.

\section{B. Monopole antenna on shoe toe-box with phantom foot}

The installed performance of the candidate antenna type was assessed when overlaid on the toe-box of the shoe, as shown in Fig. 4. A range of azimuth angles were considered on the toe-box area on account of the irregular fit of the foot-shaped permittivity with the inside of the shoe, as shown in Fig. 5.

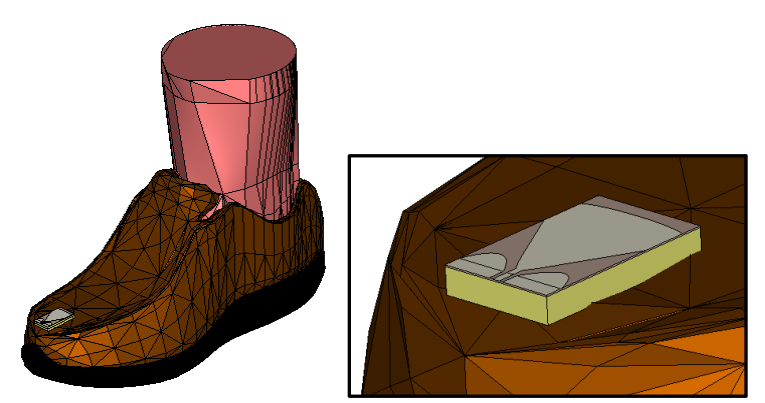

Fig. 4. Velcro monopole antenna located on the phantom-loaded shoe toe-box. 


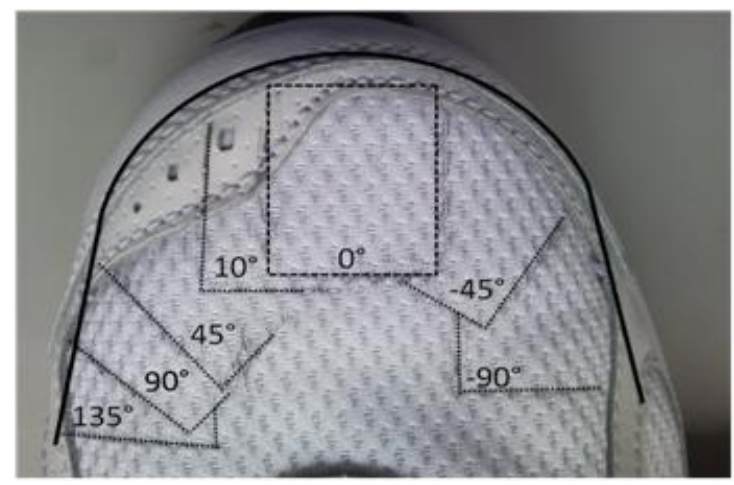

Fig. 5. Different toe-box angle positions in terms of $\varphi$ angle.

The $S_{11}$ measurement for the different positions is shown in Fig. 6 and indicates that the antenna remained tuned to the $6-8.5 \mathrm{GHz}$ bandwidth and relatively insensitive to the variation of loading.

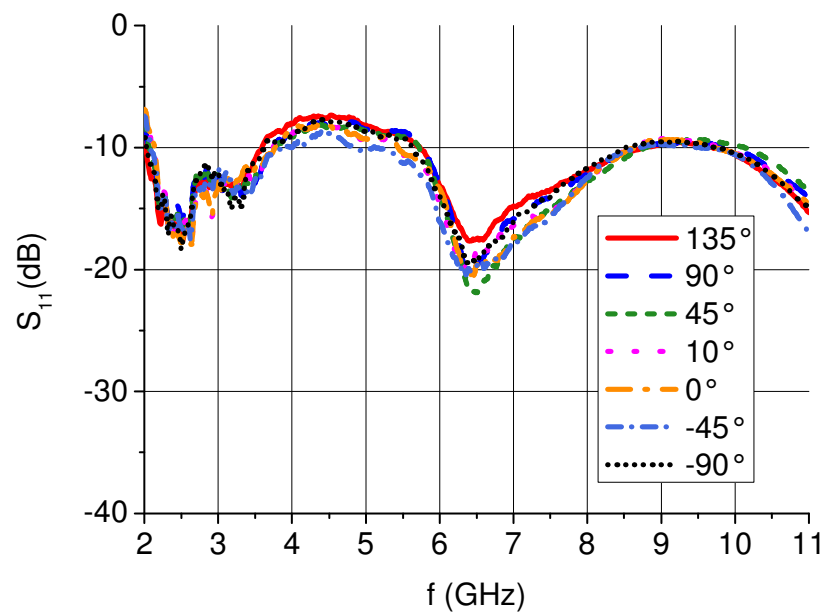

Fig. 6. $\mathrm{S}_{11}$ measurements across $90^{\circ}<\varphi<135^{\circ}$ angles of the toe-box area.

Fig. 7 contrasts the $S_{11}$ for the simulated and measured phantom loaded shoe. Placing a human foot in the shoe produces similar results to the phantom. For comparison purposes, the empty shoe will also operate with a suitably matched impedance bandwidth. The radiation patterns are shown in Fig. 8 and in Fig. 9. The omnidirectional characteristic exhibited in free-space changed predominantly in the back-lobe due to the presence of the human body. This corresponded with an increase in the realized gain in the $\theta=0^{\circ}$ direction. While there is an approximate $3 \mathrm{~dB}$ drop in the frequency-averaged realized gain for the $-180^{\circ}<\theta<180^{\circ}$ plane compared with the empty shoe case, the average simulated realized gain is greater than $1 \mathrm{dBi}$ for the $90^{\circ}<\theta<90^{\circ}$ for all the UWB frequencies.

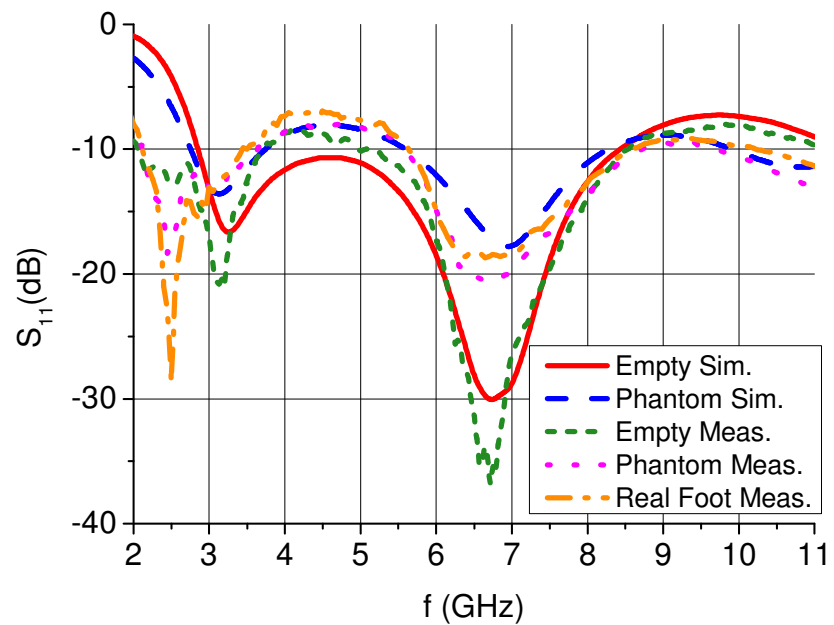

Fig. 7. $\mathrm{S}_{11}$ simulation-measurement comparison for the monopole antenna located on the toe-box of an empty/phantom/human loaded shoe. 

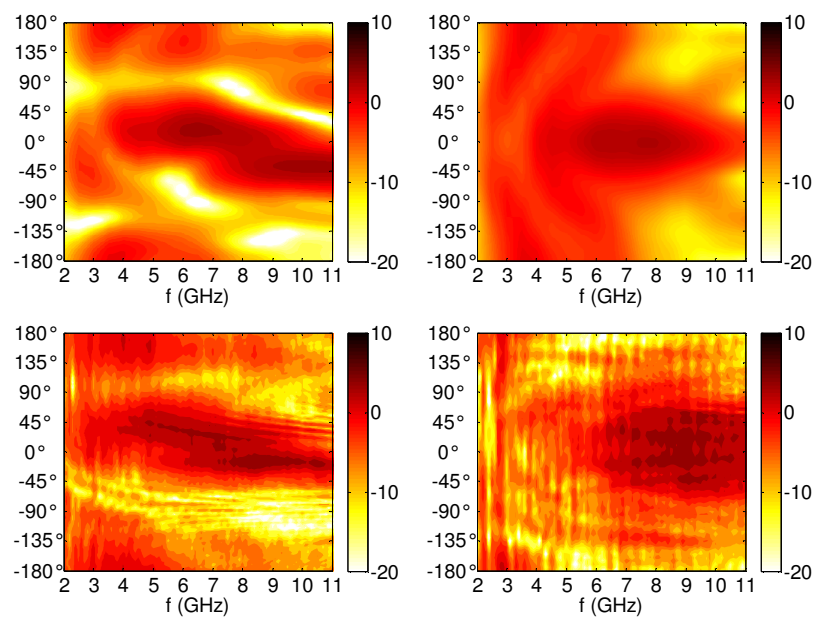

Fig. 8. Realized gain patterns ( $\mathrm{dBi}$ ) for the monopole antenna on the phantom-loaded shoe toe-box. Simulated (first row) and measured (second row) for $\varphi=0^{\circ}$ (first column) and $\varphi=90^{\circ}$ (second column).

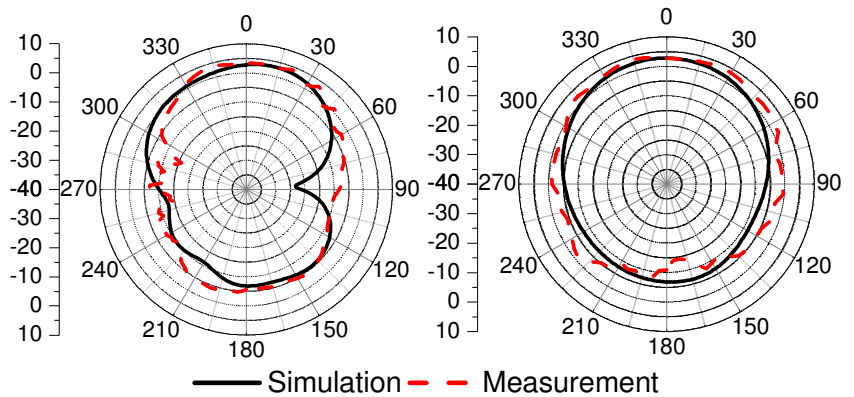

Fig. 9. Realized gain patterns $(\mathrm{dBi})$ for the monopole antenna on the phantom-loaded shoe toe-box. Simulated and measured for $\varphi=0^{\circ}$ (first) and $\varphi=90^{\circ}$ (second) at $7.25 \mathrm{GHz}$.

\section{ViVAldi ANTENNA DESIGN}

\section{A. Vivaldi Antenna}

A Vivaldi antenna, shown in Fig. 10 is designed on a single-sided FR-4 dielectric with 0.2 mm thickness for operation in the $6-8.5 \mathrm{GHz}$ bandwidth. A coplanar waveguide feed is used to match a $50 \Omega$ SMA connector to the antenna input impedance with small dimensions. One edge of the CPW forms a slot line T-junction that works as a power divider, where one side is an open circuit and the other is the Vivaldi slot [27]. Considering this geometry, the antenna has been optimized in CST to be matched in the selected bandwidth and to maximize the realized gain in the boresight direction, $\theta=0^{\circ}, \varphi=0^{\circ}$ [24].

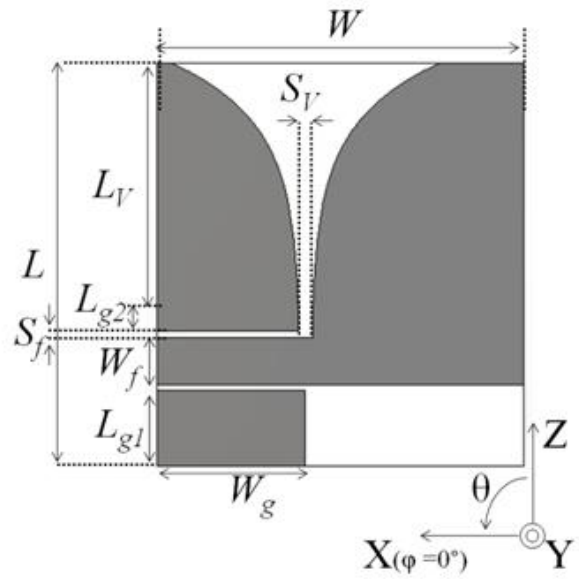

Fig. 10. Vivaldi antenna.

The optimized design parameters, shown in Fig. 10 are $L=28.6 \mathrm{~mm}, W=26.2 \mathrm{~mm}, W_{f}=3.34 \mathrm{~mm}, S_{f}=0.423 \mathrm{~mm}$, $W_{g}=10.59, L_{g l}=5.37 \mathrm{~mm}, L_{g 2}=1 \mathrm{~mm}, L_{v}=18 \mathrm{~mm}, S_{v}=1 \mathrm{~mm}$. The equation to define the flared Vivaldi curve is:

$$
0.125 * e^{0.24 L_{V}} \text { for } 0<L_{V}<18[\mathrm{~mm}]
$$

The antenna was fabricated and measured to have a $-15 \mathrm{~dB}$ bandwidth for $6-8.5 \mathrm{GHz}$ in simulation, reduced to $-14 \mathrm{~dB}$ in the measurement. The realized gain patterns are stable in the selected bandwidth. The $\varphi=90^{\circ}$ pattern is not symmetric due to the antenna geometry. Considering the $\varphi=90^{\circ}$ plane for $6-8.5 \mathrm{GHz}$, the simulated realized peak gain is $3.67 \mathrm{dBi}$ for $\theta=56^{\circ}$ 
at $8.5 \mathrm{GHz}$, with a $-3 \mathrm{~dB}$ beamwidth angle of $-85^{\circ}<\theta<87^{\circ}$. The average realized gain for this beamwidth is greater than $2 \mathrm{dBi}$ for the EU UWB spectrum. While the $\varphi=0^{\circ}$ plane $-3 \mathrm{~dB}$ beamwidth is only $74^{\circ}$, the pattern radiates adequately to the upper body area.

\section{A. Vivaldi antenna on the shoe heel counter with phantom foot}

The model of the Vivaldi antenna placed on the shoe heel counter is shown in Fig. 11. The height of the fixing position on the counter, shown in Fig. 12 was varied to evaluate the $S_{11}$ in terms of differing conductivities of the floor surfaces. The results are shown in Fig. 13. The constituent fabric materials at the three rear positions are different and exhibit the following relative permittivity values; $\varepsilon_{\mathrm{rA}}=1.9, \varepsilon_{\mathrm{rB}}=3.6, \varepsilon_{\mathrm{rC}}=3.5$. Additionally, the positions $\mathrm{B}$ and $\mathrm{C}$ are more distant from the phantom. The ground surface under the shoe was compared with a PEC layer to examine the influence of the conductivity of the antenna impedance matching. The $S_{11}$ remained matched for the UWB frequencies for the three positions. The shoe was lifted $300 \mathrm{~mm}$ above the ground surfaces to evaluate conditions of stride and again, the matching impedance was stable.
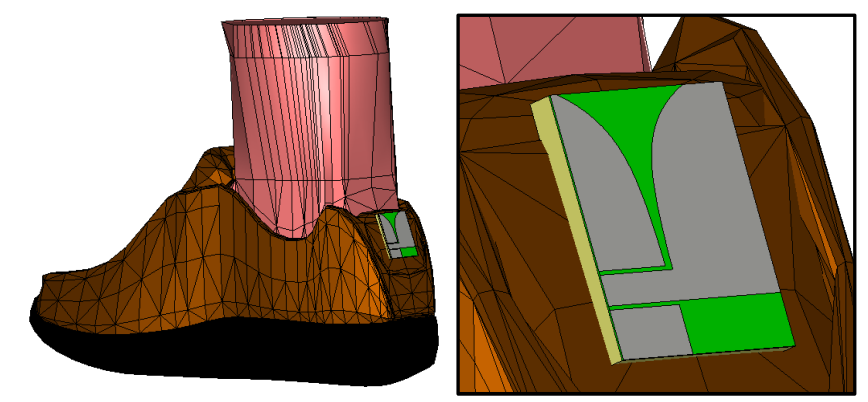

Fig. 11. Velcro Vivaldi antenna located on the phantom-loaded heel counter.

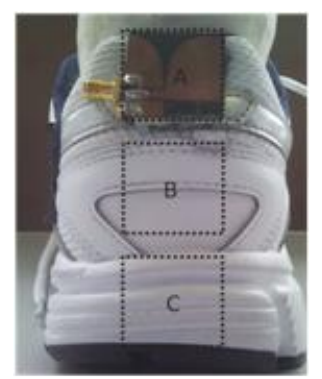

Fig. 12. Top (A), middle (B) and bottom (C) position of the Vivaldi antenna.

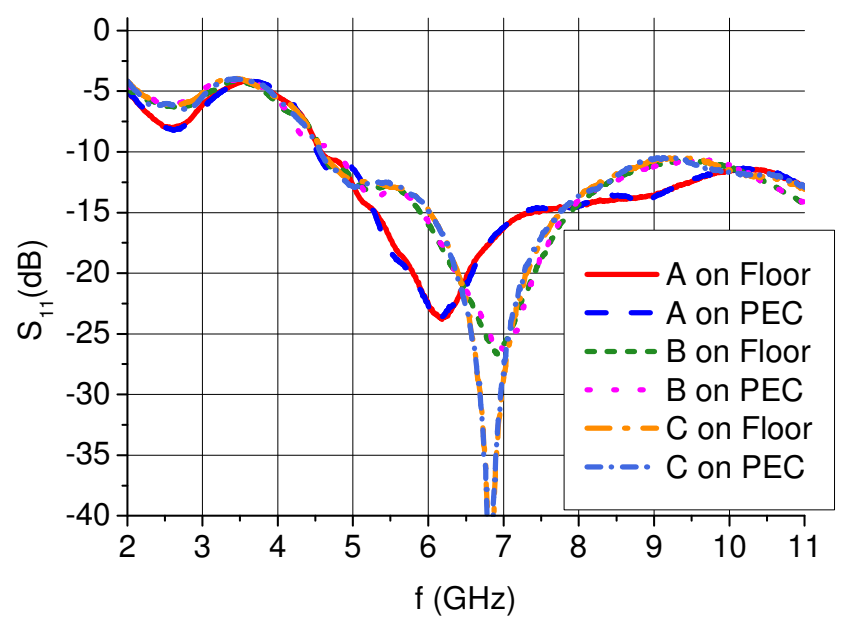

Fig. 13. $\mathrm{S}_{11}$ measurement for different antenna positions on different grounds.

Fig. 14 shows the simulated and measured results for the antenna mounted on the heel counter for the phantom-loaded shoe, the real foot-loaded shoe and the empty shoe. There is a good agreement between the simulation and the measurements. There is a frequency shift of $400 \mathrm{MHz}$ due to the dielectric load of the foot [28]. Although the simulated $6-8.5 \mathrm{GHz}$ band is matched better than $-15 \mathrm{~dB}$, the measured $S_{11}$ is reduced to $-11 \mathrm{~dB}$. The pattern comparison is shown in Fig. 15 and in Fig. 16. When mounted on the heel counter, the principle pattern points towards $\theta=27.5^{\circ}, \varphi=180^{\circ}$ with an $8.5 \mathrm{dBi}$ gain at $8.5 \mathrm{GHz}$. The common $-3 \mathrm{~dB}$ beamwidth across $6-8.5 \mathrm{GHz}$ is $20^{\circ}<\theta<35^{\circ}, \varphi=180^{\circ}$. While the heel counter aligns the antenna towards the body, the main radiation lobe is pointing to an off-body direction. This is attributed to the high reflection coefficient due to the high permittivity of the body tissues. 


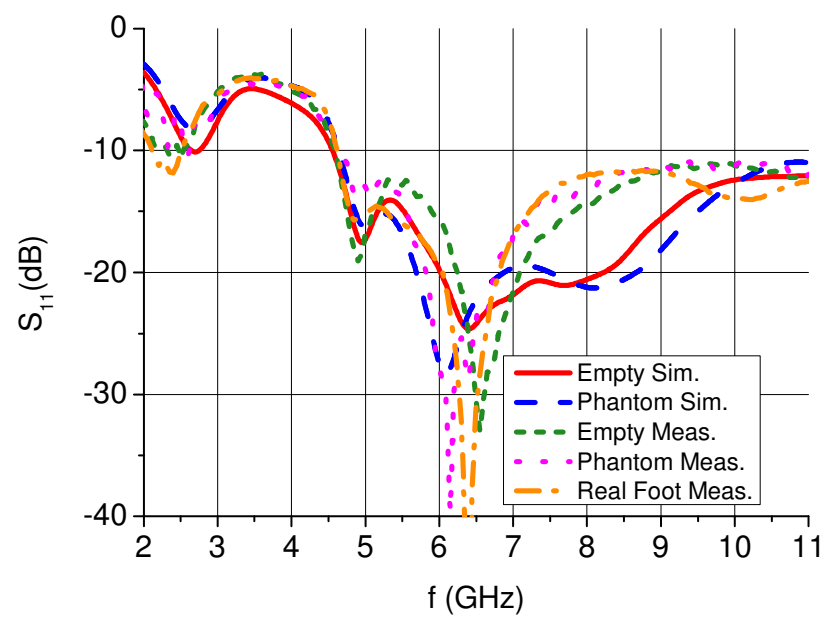

Fig. 14. $\mathrm{S}_{11}$ simulation-measurement comparison for the Vivaldi antenna located on the heel counter of an empty/phantom/human loaded shoe.
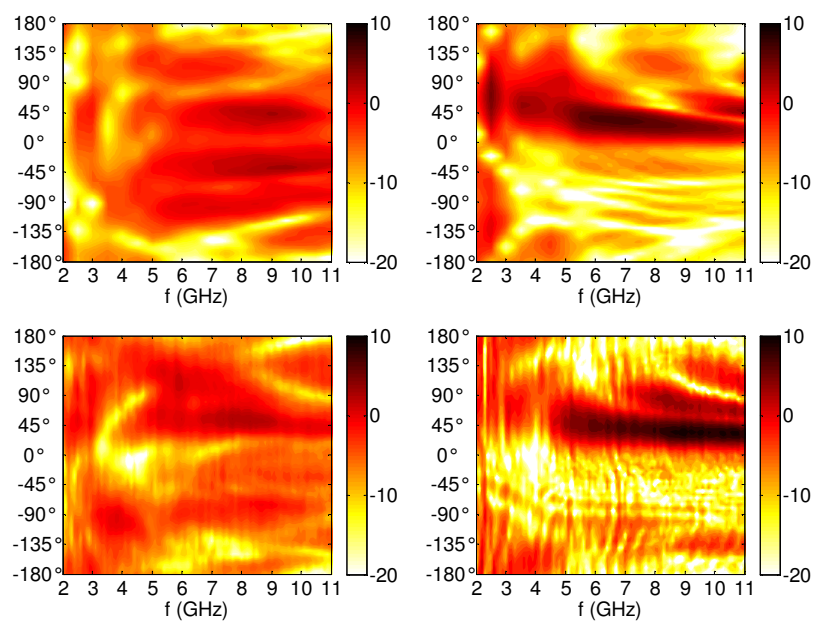

Fig. 15. Realized gain patterns (dBi) for the Vivaldi antenna on the heel counter of the phantom-loaded shoe. Simulated (first row) and measured (second row) for $\varphi=90^{\circ}$ (first column) and $\varphi=180^{\circ}$ (second column).
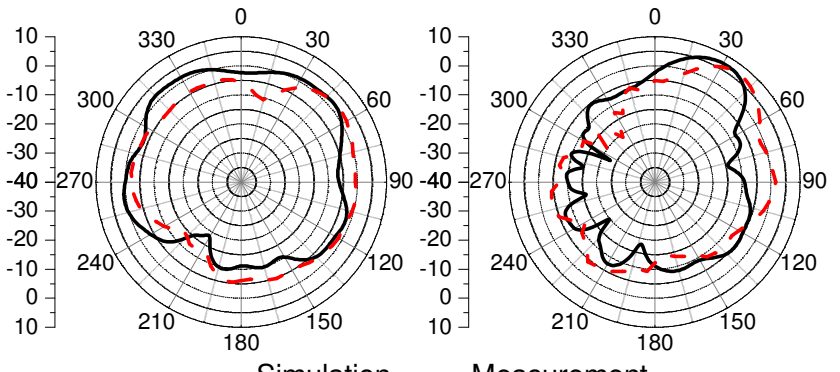

Fig. 16. Realized gain patterns (dBi) for the heel counter Vivaldi antenna simulated and measured for $\varphi=90^{\circ}$ (first) and $\varphi=180^{\circ}$ (second) at $7.25 \mathrm{GHz}$.

\section{A. Vivaldi antenna on shoe lateral quarter with phantom foot}

The lateral quarter of the shoe, shown in Fig. 17, was selected for its increased rigidity compared with the vamp (midfoot) area which flexes with the kinematic function of the foot. The $S_{11}$ results are shown in Fig. 18. The phantom loaded response is similar to that of a real foot and while the frequency shifts down the antenna remains impedance matched. The pattern comparisons are shown in Fig. 19 and in Fig. 20. The beam shape remains consistent in the UWB frequency range. The maximum realized gain is equal to $7.32 \mathrm{dBi}$ at $\theta=50^{\circ}, \varphi=90^{\circ}$ with a $-3 \mathrm{~dB}$ beamwidth of $40^{\circ}<\theta<72^{\circ}$. 


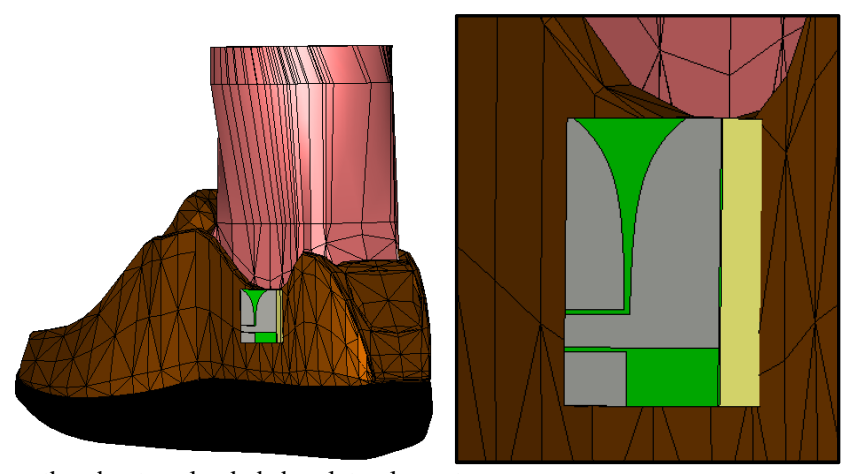

Fig. 17. Velcro Vivaldi antenna located on the phantom-loaded shoe lateral quarter.

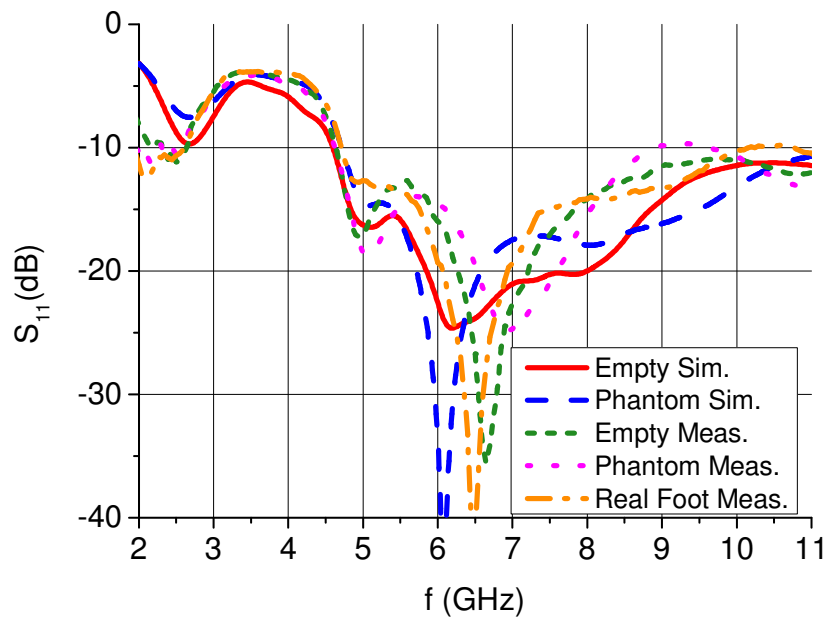

Fig. 18. $\mathrm{S}_{11}$ simulation-measurement comparison for the Vivaldi antenna located on the lateral quarter of an empty/phantom/human loaded shoe.
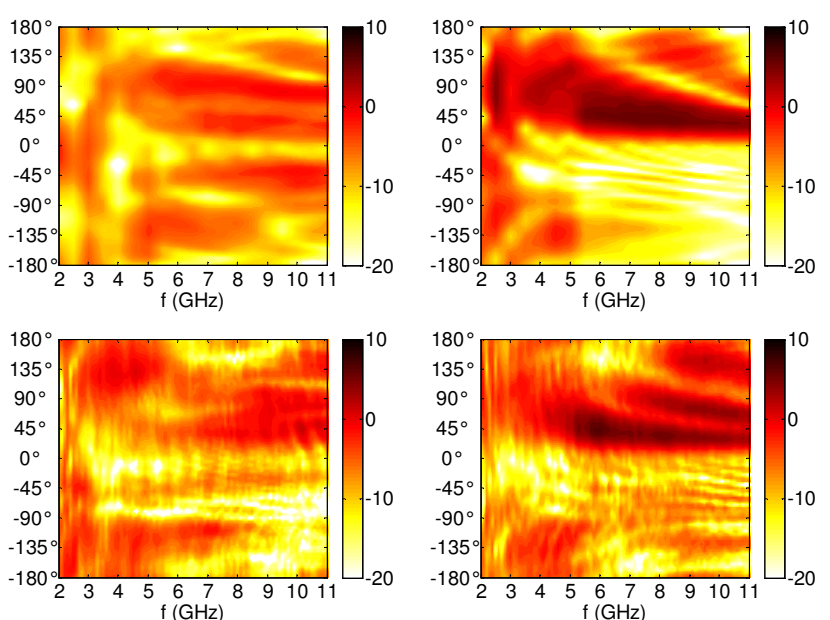

Fig. 19. Realized gain patterns ( $\mathrm{dBi}$ ) for the Vivaldi antenna on the lateral quarter of the phantom-loaded shoe. Simulated (first row) and measured (second row) for $\varphi=0^{\circ}$ (first column) and $\varphi=90^{\circ}$ (second column).

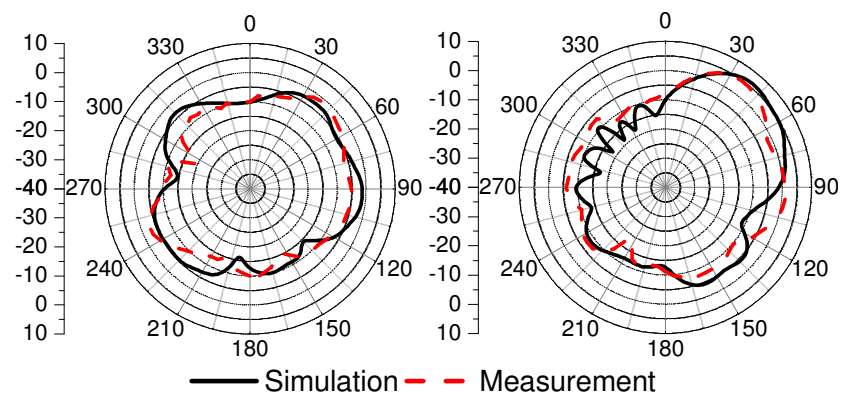

Fig. 20. Realized gain patterns (dBi) for the lateral quarter Vivaldi antenna simulated and measured for $\varphi=0^{\circ}$ (first) and $\varphi=90^{\circ}$ (second) at $7.25 \mathrm{GHz}$. 


\section{ANALYSIS OF HUMAN GAIT}

The distribution of the E-field [2], [4], [29], [30] is investigated to gauge the effects of the path loss, multipath, and shadowing that would occur between footwear antennas and the upper/off-body areas. While the E-field is strictly correlated to the $S_{21}$, simulated analysis using a second receiving antenna would have influenced the results in terms of its polarization, alignment, efficiency and match characteristics, et cetera. The E-field intensity for the upper body areas provides generic insight for the performances of the footwear antennas and their positions. The E-field is inspected at the $7.25 \mathrm{GHz}$ center frequency at the upper body areas and the reported values were normalized with respect to the maximum value at the antenna feed.

Three full body models, which were selected from a 120 frame walking-cycle sequence using the Make Human software application, are shown in Fig. 21. The models represent a 25 year old female, $1.68 \mathrm{~m}$ in height, for the walking phases of left-leg terminal-swing phase (pose frame 7), left-leg mid-stance (pose frame 40) and the left-leg toe-off (pose frame 85) [31].

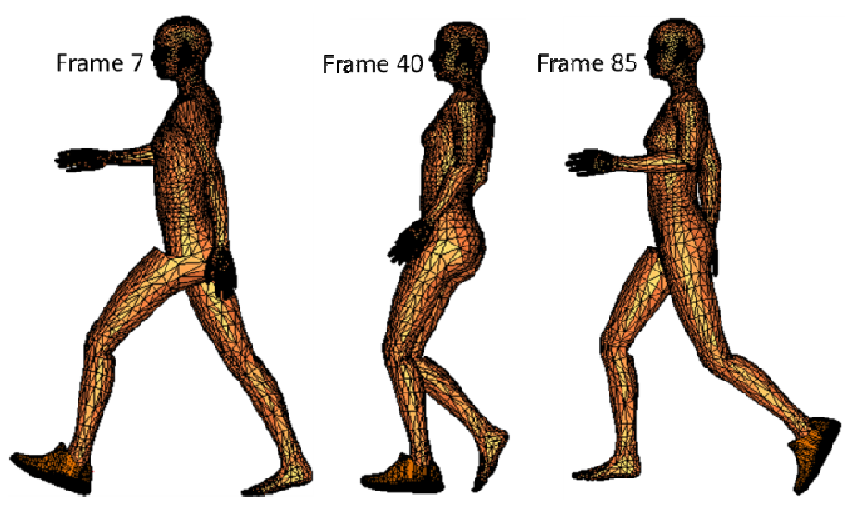

Fig. 21. CST models of three phases of human gait motion; left-leg terminal-swing phase, left-leg mid-stance and left-leg toe-off.

The poses summarize the maximum stride ranges and the mid-stride position of the human gait cycle. For partial indoor conditions, the models were configured above a steel-reinforced concrete floor surface [32]. The human body is characterized as $2 / 3^{\text {rd }}$ the electrical properties of the muscle. Five locations were selected shown in Fig. 22, namely the left waist, the left upper arm, the sternum area, the $4^{\text {th }}$ vertebrae area and off-body at $1 \mathrm{~m}$ distant from the shoulder.

These positions represent communication scenarios for links with the foot area; a waist-belt clipped device, an arm strapped device, chest and back sensors or an off-body device. The simulated normalized E-field values are reported in Table II from inspecting $\pm 2.5 \mathrm{~dB}$ resolution field plots of the received fields at the upper-body probe points. The fluctuations are due to body or hand shadowing during gait. An off-body link at shoulder height with $1 \mathrm{~m}$ distance was used to evaluate the footwear antenna performances with the least shadowing from the limbs or torso. The $\mathrm{E}_{\text {field }}$ values were consistently the best for the three footwear positions across the gait cycle.

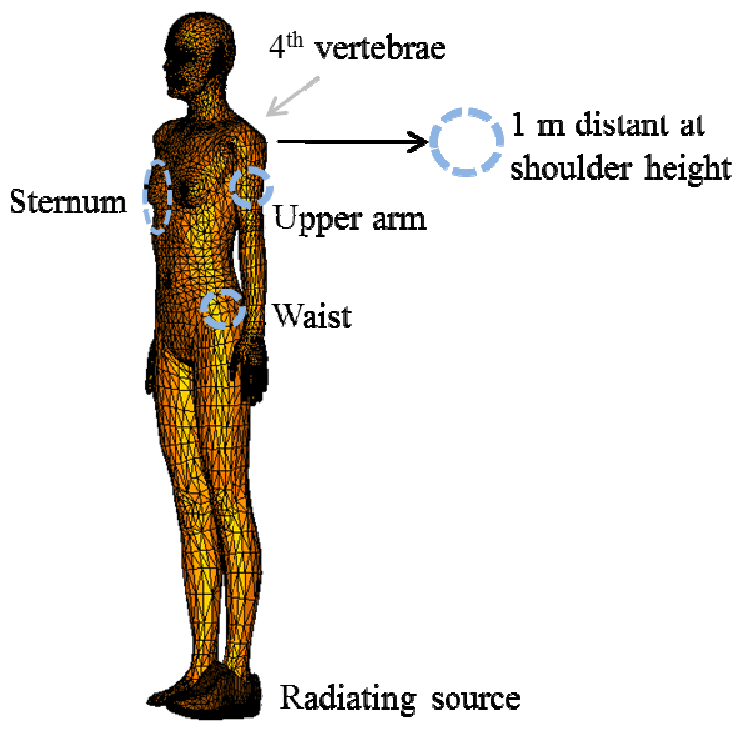

Fig. 22. E-field monitoring positions. 
TABLE II

NORMALIZED E-FIELD (dB) TO UPPER BODY POSITIONS

\begin{tabular}{|c|c|c|c|c|c|c|c|c|c|}
\hline Position & \multicolumn{3}{|c|}{ Toe-box } & \multicolumn{3}{|c|}{ Lateral Quarter } & \multicolumn{3}{|c|}{ Heel Counter } \\
\hline Pose frame number & [7] & {$[40]$} & [85] & [7] & {$[40]$} & [85] & [7] & {$[40]$} & [85] \\
\hline $1 \mathrm{~m}$ from shoulder & -75 & -70 & -80 & -75 & -80 & -82.5 & -80 & -80 & -80 \\
\hline Upper arm & -75 & -80 & -90 & -85 & -85 & -82.5 & -90 & -90 & -75 \\
\hline Sternum area & -65 & -70 & -90 & -90 & -90 & -90 & -90 & -100 & -95 \\
\hline $4^{\text {th }}$ Vertebrae & -77.5 & -90 & -80 & -100 & -80 & -75 & -95 & -90 & -70 \\
\hline Waist & -90 & -85 & -85 & -80 & -85 & -85 & -85 & -85 & -85 \\
\hline
\end{tabular}

The toe-box antenna has a good connection with the upper arm until the shadowing in the left-leg toe-off stance degrades it. While the lateral quarter antenna link to the upper arm incurs less variability, the heel counter design is the most effective when the heel rises in the left-leg toe-off. Direct line of sight conditions produce the least loss of $-65 \mathrm{~dB}$ for full leg extensions, i.e. the toe-box antenna connects to the sternum area or correspondingly the heel counter antenna with the $4^{\text {th }}$ vertebrae area for frame 85 . However, with the opposite stance the loss increases by circa $25 \mathrm{~dB}$. In contrast, the lateral quarter antenna connectivity to the sternum area is steady at $-90 \mathrm{~dB}$ for each stance, while it fluctuates by $25 \mathrm{~dB}$ in the $4^{\text {th }}$ vertebrae area. This is attributed to shadowing from the arm swing or the torso. Connectivity to the waist is the least to fluctuate during the gain cycle, with some shadowing of the hand producing additional reduction from a typical $-85 \mathrm{~dB}$ value. If a combination of antennas were considered from the three positions on the foot, a maximum link loss level of $-90 \mathrm{~dB}$ would be achieved.

The range of values in Table 2 indicates the impact of shadowing, multipath and line of sight performances on the various footwear antennas positions for connection with the upper-body areas. In general, the toe-box monopole antenna offers a good communication link for the ventral side of the coronal plane which is suited to front belt clip or handheld devices. Alternatively, the Vivaldi antennas provide good coverage for dorsal side of the coronal plane and a one side of the sagittal plane.

\section{CONCLUSION}

Techniques for researching the design of antennas for UWB $6-8.5 \mathrm{GHz}$ for footwear sensors are reported using modeling and prototype measurements. A monopole antenna and a Vivaldi antenna design are proposed for three mounting positions on a shoe. Characteristic simulated shoe and foot models were derived from measurements of both material properties and geometric shapes of the shoe and a fabricated homogeneous foot phantom.

The antenna performances were considered for the positions on the shoe, impact of the dielectric loads on the phantom and a real foot, proximity to the floor surface and for communication link performances with the upper-body and off-body areas. The monopole antenna located on the toe-box of the shoe proved insensitive to the irregularly shaped dielectric load of the toe features in the shoe. The principle radiating lobe was towards the upper body area with minimal energy lost towards the foot. The Vivaldi antenna design was mounted on the lateral quarter of the shoe and produced a radiation pattern that deflected away slight from the upper body area. The beamwidth angles were comparatively broad. When mounted on the heel counter, the Vivaldi design again produced a deflected pattern to the upper dorsal area. The beamwidth was slightly reduced compared with the lateral quarter mounting. The design was insensitive to the mounting height over the floor surface beneath the shoe and it was compatible with the varying rubber and plastic materials that make up the shoe.

The normalized E-field intensity results for the various footwear antennas and postures were examined to gauge the connectivity between with the upper body and off-body areas. Localized shadowing effects may be overcome for more sensitive applications by using combinations of antennas on the footwear.

The results qualify the performances of the various footwear-integrated antenna designs, positions and human postures. Real-time data over short on-body and off-body radio links can enable high-speed analysis of gait and kinetics, in addition to environmental sensing for occupational purposes.

\section{ACKNOWLEDGMENT}

The authors would like to thank Colm Brannigan at the Royal College of Surgeons in Ireland for his assistance.

\section{REFERENCES}

[1] T. S. See and Z. N. Chen, "Experimental Characterization of UWB Antennas for On-Body Communications," IEEE Trans. Antennas Propag., vol. 57, pp. 866-874, 2009.

[2] G. A. Conway and W. G. Scanlon, "Low-Profile Patch Antennas for Over-Body-Surface Communication at 2.45 GHz," in International Workshop on Antenna Technology: Small and Smart Antennas Metamaterials and Applications, 2007. IWAT '07, 2007.

[3] A. Alomainy, A. Sani, A. Rahman, J. G. Santas and Y. Hao, "Transient Characteristics of Wearable Antennas and Radio Propagation Channels for Ultrawideband Body-Centric Wireless Communications," IEEE Trans. Antennas Propag., vol. 57, pp. 875-884, 2009.

[4] N. Chahat, M. Zhadobov, R. Sauleau and K. Ito, "A Compact UWB Antenna for On-Body Applications," IEEE Trans. Antennas Propag., vol. 59, pp. 1123-1131, 2011. 
[5] Z. Duan, D. Linton, W. Scanlon and G. Conway, "Improving wearable slot antenna performance with EBG structures," in LAPC Antennas and Prop. Conf., Loughborough, 2008.

[6] C. Hertleer, H. Rogier, L. Vallozzi and L. Van Langenhove, "A Textile Antenna for Off-Body Communication Integrated Into Protective Clothing for Firefighters," IEEE Trans. Antennas Propag., vol. 57, no. 4, pp. 919-925, 2009.

[7] A. Sani, A. Alomainy, G. Palikaras, Y. Nechayev, Y. Hao, C. Parini and P. S. Hall, "Experimental Characterization of UWB On-Body Radio Channel in Indoor Environment Considering Different Antennas," IEEE Trans. Antennas Propag., vol. 58, pp. 238-241, 2010.

[8] Y. Hao and R. Foster, "Wireless body sensor networks for health-monitoring applications," Physiological Measurement, vol. 29, no. 11, pp. R27R56, 2008.

[9] S. J. Morris and J. A. Paradiso, "A Compact Wearable Sensor Package for Clinical Gait Monitoring," Offspring, vol. 1, no. 1, pp. 7-15, 2003.

[10] I. Makris, D. Manteuffel and R. D. Seager, "Miniaturized reconfigurable UWB antennas for the integration into consumer electronic products," IET Digest, vol. 2007, pp. 718-718, 2007.

[11] S. J. Morris and J. A. Paradiso, "Interactive Music for Instrumented Dancing Shoes," in International Computer Music Conference (ICMC), Bejing, 1999.

[12] B. Sanz-Izquierdo, J. Miller, J. Batchelor and M. Sobhy, "Dual-band wearable metallic button antennas and transmission in body area networks," Microwaves, Antennas \& Propagation, IET, vol. 4, no. 2, pp. 182-190, 2010.

[13] I. Khan, P. Hall, A. Serra, A. Guraliuc and P. Nepa, "Diversity Performance Analysis for On-Body Communication Channels at 2.45 GHz," IEEE Trans. Antennas Propag., vol. 57, no. 4, pp. 956-963, 2009.

[14] L. Ma, R. Edwards and W. Whittow, "A notched hand wearable ultra wideband W printed monopole antenna for sporting activities," in $L A P C$ Antennas and Propag. Conf., Loughborough, 2008.

[15] S. Wang, J. Zavala and C. D. Prest, "Antennas for compact portable wireless devices". United States of America Patent 577,102, 4 February 2010.

[16] C. Zhou, J. Downey, D. Stancil and T. Mukherjee, "A Low-Power Shoe-Embedded Radar for Aiding Pedestrian Inertial Navigation," IEEE Trans. on Microw. Theory Techn., vol. 58, pp. 2521-2528, 2010.

[17] M. W. Jamel, P. E. Bertagna and R. H. Davis., "Footwear with GPS". United States of America Patent 41,087, 26 January 2010.

[18] G. Orecchini, L. Yang, M. M. Tentzeris and L. Roselli, "'Smart Shoe": An autonomous inkjet-printed RFID system scavenging walking energy," in IEEE Internat. Symp. Ant. and Propag. (APSURSI), 2011.

[19] "Blender Foundation," [Online]. Available: http://www.blender.org/.

[20] T. P. Marsland and S. Evans, "Dielectric measurements with an open-ended coaxial probe," IEE Proc. Microw., Ant. and Propag., vol. 134, pp. 341-349, 1987.

[21] K. Ito, "Human Body Phantoms for Evaluation of Wearable and Implantable Antennas," in The Second European Conference on Antennas and Propagation, 2007 EuCAP 2007, 2007.

[22] Q. Bai and R. Langley, "Crumpled textile antennas," Electron. Lett., vol. 45, pp. 436-438, 2009.

[23] "Make Human," [Online]. Available: http://www.makehuman.org/.

[24] M. John and M. J. Ammann, "Antenna Optimization With a Computationally Efficient Multiobjective Evolutionary Algorithm," IEEE Trans. Antennas Propag., vol. 57, pp. 260-263, 2009.

[25] J. Liang, C. C. Chiau, X. Chen and C. G. Parini, "Study of a printed circular disc monopole antenna for UWB systems," IEEE Trans. Antennas Propag., vol. 53, pp. 3500-3504, 2005.

[26] Z. N. Chen, "Small Printed Ultrawideband Antenna With Reduced Ground Plane Effect," IEEE Trans. Antennas Propag., vol. 55, pp. 383-388, 2007.

[27] K. C. Gupta, Microstrip Line and Slotlines, Artech House Inc: Norwood, 1996, p. 436-439.

[28] D. Tsamakis and Z. Wu, "Modeling and experimental study of dielectric loaded monopoles for UWB applications," in IEEE Anten. and Propag. Soc. Internat. Symp., 2007.

[29] G. A. Conway and W. G. Scanlon, "Antennas for Over-Body-Surface Communication at 2.45 GHz," IEEE Trans. Antennas Propag., vol. 57, no. 4, pp. 844-855, 2009.

[30] K. Fujii, M. Takahashi, K. Ito and N. Inagaki, "Study on the electric field distributions around whole body model with a wearable device using the human body as a transmission channel," in Antennas and Propagation EuCAP, Nice, 2006.

[31] H. G. Chambers and D. H. Sutherland, "A Practical guide to Gait Analysis," J. Am. Acad. Orthop. Surg. , vol. 10, pp. $222-231$, 2002.

[32] R. A. Dalke, C. L. Holloway and P. McKenna, "Effects of Reinforced Concrete Structures on RF Communications," IEEE Trans. Electrom. Comp., vol. 42, no. 4, pp. 486-496, 2000.

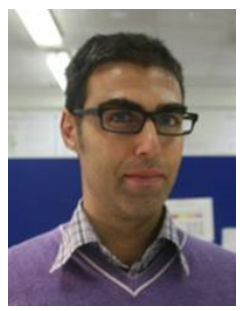

Domenico Gaetano (S'13) received the M.S. degree in Telecommunication Engineering from the University of Calabria, Italy, in July 2009. He undertook an internship with the Wireless Sensing System Group, Tyndall National Institute, Cork, Ireland in 2008.He is currently a Ph.D. student at the Antenna and High Frequency Research Centre, Dublin Institute of Technology, Ireland. His research interests include ultra wideband communications, body area wireless communications and wireless telemetry for physiotherapy and sporting applications.

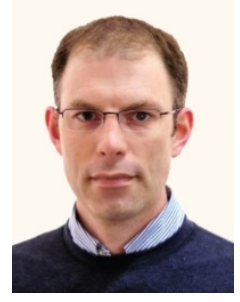

Patrick McEvoy (M'02) received the Dip.EE degree in Telecommunications and Electronic Engineering from the Dublin Institute of Technology, Dublin, Ireland, in 1995, the M.Eng. degree in Electronic Communications Engineering from the University of Hull, Hull, U.K. (with studies at L'Institut Supérieur d'Electronique de Paris, France), in 1998, and the Ph.D. degree in microwave antenna engineering from Loughborough University, Leicestershire, U.K., in 2007.

Currently, he is a Senior Researcher at the Antenna and High Frequency Research Centre, Dublin Institute of Technology (DIT). Prior to joining the DIT he was a Research Manager at the Centre for Mobile Communications Research, Loughborough University, where he worked on switched antennas for handheld terminals, applications of metamaterials, low specific absorption rate antenna design and antenna measurement systems. He has fifteen years of applied academic research and industrial experience that includes design, high-volume manufacturing and measurement systems for miniaturized microwave antennas. His main research interests include the electromagnetic interaction antenna-human tissue, hyperthermia applicators, microwave imaging, body area communications, ultra wideband antennas for frequency and time-domain applications and the integration of antennas with solar voltaic devices. He has published over 71 scientific papers 
and has helped to organize four international conferences on antennas and propagation. Dr. McEvoy is a co-recipient of two awards for industrial commercialization of researched antenna technologies.

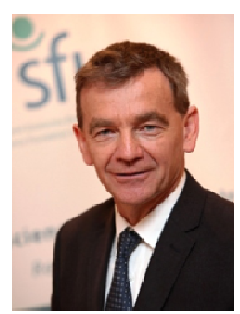

Max J. Ammann (M'96-SM'08) received the Council of Engineering Institution Part II degree in 1980 and the Ph.D. degree in microwave antenna design from Trinity College, University of Dublin, Dublin, Ireland, in 1997.

$\mathrm{He}$ is a Senior Lecturer in the School of Electronic and Communications Engineering, Dublin Institute of Technology, where he is the Director of the Antenna and High Frequency Research Centre. He also leads the antenna research within Ireland's Telecommunications Research Centre (CTVR), Dublin. He spent eight years on radio systems engineering and antenna design for TCL/ Philips Radio Communications Systems, Dublin, where he was responsible for commissioning the Nationwide Communications Network for Ireland's national police force. In 1986 he joined the DIT as a Lecturer and was promoted to Senior Lecturer in 2003 and honorary professor in 2012. His research interests broadly include electromagnetic theory, antenna miniaturization for terminal and ultra wideband applications, microstrip antennas, antennas for medical devices and the integration with photovoltaic systems. He has in excess of 200 peer-reviewed papers published in journals and international conferences. He has served as an expert to industry on various antenna technologies in the communications, medical, aviation and electronic security sectors in Ireland and abroad. The roles have included design assessment, design solutions, technological strategy reporting and assessment of compliance with international standards on human exposure to electromagnetic energy. The industrial contacts also stem from several successful transfers of fundamental design research into applied solutions.

Dr. Ammann received a best paper award at the 2006 Loughborough Antennas and Propagation Conference, the 2009 SFI best paper award in the China Ireland International Conference in ICT and commercialization awards for work with DecaWave Ltd, Taoglas Ltd and Sequoia Smart Solutions. He also received a 2008 CST University Publication Award for work on a "Wideband Reconfigurable Rolled Planar Monopole Antenna" and a 2011 CST Award for work on "Miniature Ceramic Dual-PIFA Antenna to Support Band Group 1 UWB Functionality in Mobile Handset". He sits on the management committee of the EU COST Action IC1102, "Versatile, Integrated, and Signal-aware Technologies for Antennas (VISTA)" and is active in the EurAAP working group on small antennas. As a member of the IEEE International Committee for Electromagnetic Safety, he participated in the revision of the IEEE Std. C95.1, 2005 \& 2012 standards for Safety Levels with Respect to Human Exposure to Radio Frequency Electromagnetic Fields, 3 kHz to 300 GHz. He is also a member of the URSI Committee for Communications and Radio Science within the Royal Irish Academy and official member of URSI Commission K: Electromagnetics in Biology and Medicine. He has chaired and organized special sessions on small antennas, UWB antennas and UWB Wireless Communication Systems at EuCAP and IEEE APS and chaired the Antennas and Propagation Track for the 65th IEEE VTC, Dublin 2007. He was the local chair for the October 2008 EU COST IC0603 workshop and meeting in Dublin. He is currently associate editor for the IEEE Antennas \& Wireless Propagation Letters.

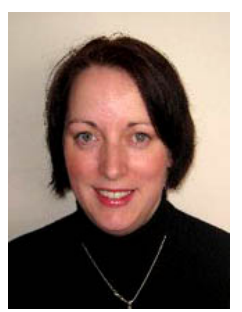

Jacinta E. Browne is a Lecturer in School of Physics in the Dublin Institute of Technology. She received a BSc (Hons) degree, as well as an MSc degree from Trinity College, University of Dublin in 1997 and 2000 and a PhD. Degree in ultrasound physics from the University of Glasgow in 2003. She is a Fellow of the Institute of Physics and Engineering in Medicine and is a Chartered Physicist with the Institute of Physics. Her research interests include ultrasound physics and the development of tissue mimicking phantoms for biomedical applications.

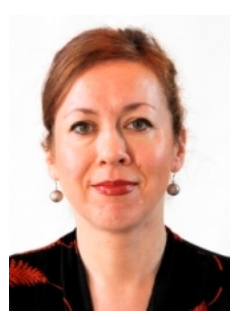

Louise Keating is a Lecturer in Physiotherapy at the Royal College of Surgeons in Ireland (RCSI). She is a graduate of University College Dublin, and holds a BSc (Hons) degree, as well as an MPhytySt (Manipulative) degree from the University of Queensland. She is a committee member on several Irish Society of Chartered Physiotherapists (ISCP) groups, such as Chartered Physiotherapist in Musculoskeletal Therapy (CPMT), and is also a titled member (musculoskeletal) of Musculoskeletal Physiotherapy Australia (MPA). Her research interests include assessment and management of spinal pain and more recently, the effectiveness and impact of in-shoe orthotics in sport.

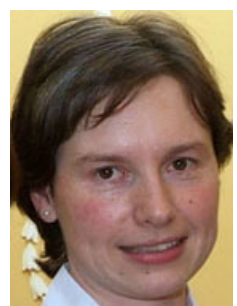

Frances Horgan is a Senior Lecturer at the Royal College of Surgeons in Ireland (RCSI) School of Physiotherapy. She is a graduate of the University of Dublin Trinity College (TCD), and holds a BSc (Hons) degree, MSc (Research), Diploma in Statistics and PhD degrees from TCD. She is a member of the Irish Society of Chartered Physiotherapists (ISCP), the Irish Society of Chartered Physiotherapists in Neurology and Gerontology, and the Irish Gerontological Society. Her research interests are care of the elderly, balance, instability and the impact of footwear on balance, falls and stroke rehabilitation. Dr Horgan has been conducting research on footwear and falls risk factors in two large Dublin teaching hospitals for several years. These projects have focused on the impact of different types of footwear on balance, footwear, ankle and foot problems as risk factors for falling. She has grant funding and publications in stroke and elderly rehabilitation. 